\title{
Solubilization of Peripheral Benzodiazepine-binding Sites from Rat Kidney ${ }^{1}$
}

\author{
MOSHE GAVISH² AND FUAD FARES
} Rappaport Family Institute for Research in the Medical Sciences and Department of Pharmacology, Faculty of Medicine, Technion-
Israel Institute of Technology, P. O. Box 9697, Haifa 31096, Israel

\begin{abstract}
The ability of a variety of detergents to solubilize peripheral benzodiazepine-binding sites from rat kidney was tested. Of all the detergents tested, only digitonin was found to be suitable for solubilization. This detergent solubilized $21 \%$ of the binding activity; $47 \%$ was inactivated, and $32 \%$ remained in the pellet. Specific binding of $\left[{ }^{3} \mathrm{H}\right] \mathrm{Ro}$ 5-4864 to membranebound and solubilized peripheral benzodiazepine-binding sites was saturable, yielding a linear Scatchard plot $(r=$ $0.96)$. $K_{\mathrm{D}}$ values obtained for the membrane-bound and solubilized peripheral benzodiazepine binding sites were $3.9 \pm$ $0.4 \mathrm{~nm}$ and $5.4 \pm 0.4 \mathrm{~nm}$, respectively. Respective $B_{\max }$ values were $4.6 \pm 0.5$ and $1.9 \pm 0.2 \mathrm{pmol} / \mathrm{mg}$ of protein. The $K_{D}$ value for the solubilized material obtained from kinetic experiments was $5.3 \pm 0.6 \mathrm{nM}$. The potency of PK 11195, Ro 54864, diazepam, flurazepam, chlordiazepoxide, Ro 15-1788, methyl- $\beta$-carboline-3-carboxylate, and clonazepam to displace bound $\left[{ }^{3} \mathrm{H}\right] \mathrm{Ro}$ 5-4864 from peripheral binding sites was similar in the membrane-bound and the soluble states. Most of the binding activity of the solubilized binding sites was destroyed by heating at $60^{\circ} \mathrm{C}$ for $30 \mathrm{~min}$ or by treatment with $2 \mathrm{~m}$ guanidinium chloride or $4 \mathrm{M}$ urea. More than $95 \%$ of the binding activity of the solubilized binding sites was retained after $18 \mathrm{hr}$ at $4^{\circ} \mathrm{C}$, and more than $60 \%$ was retained after 4 days at the same temperature. These results indicate that the binding characteristics of peripheral benzodiazepinebinding sites extant in the membrane-bound state are retained after solubilization.
\end{abstract}

The discovery of high affinity benzodiazepine (BZ)-binding sites in the CNS (Squires and Braestrup, 1977; Mohler and Okada, 1977) promoted studies which have shed light on the understanding of the GABA/BZ receptor complex. It has been found that the binding of various $B Z s$ to these sites correlates with their clinical potency as anticonvulsants and anxiolytics (Mohler et al., 1978). The solubilization of the central BZ receptors (Gavish et al., 1979; Lang et al., 1979; Yousuli el al., 1979; Sherman-Gold and Dudai, 1980; Stephenson and Olsen, 1982) was an important step in the characterization (Gavish and Snyder, 1980; Chang et al., 1982; Gavish, 1983)

Received October 22, 1984; Revised February 21, 1985;

Accepted March 19, 1985

\footnotetext{
${ }^{1}$ This work was supported by grants from the M. Hedson Foundation for Medical Research and the Bat-Sheva de Rothschild Foundation.

${ }^{2}$ To whom correspondence should be addressed, at Rappaport Family Institute for Research in the Medical Sciences and Department of Pharmacology, Faculty of Medicine, Technion-Israel Institute of Technology, P. O. Rox 9697, Haifa 31096, Israel.
}

and partial purification (Gavish and Snyder, 1981; Martiri et al., 1982 Schoch and Mohler, 1983; Sigel and Barnard, 1984) of the GABA/ $B Z$ receptor complex. In addition to the "central" $B Z$ receptors mentioned above, another type of BZ-binding site has been located, initially in peripheral tissues such as platelets (Wang et al., 1980), mast cells (Taniguchi et al., 1980), thymocytes (Wang et al., 1981), heart (Davies and Huston, 1981; Taniguchi et al., 1982), and kidney (Taniguchi et al., 1982), but also in the brain (Schoemaker et al., 1981; Marangos et al., 1982; Weissman et al., 1984). Peripheral binding sites are different from central BZ receptors in their distribution within the brain, their specificity for ligand binding, and their lack of coupling to the GABA receptor. As a first step toward purification of peripheral BZ-binding sites, we conducted solubilization experiments on rat kidney, which is rich in peripheral BZ-binding sites which are similar in their drug specificity to the peripheral BZbinding sites in the brain. Active Triton X-100-solubilized peripheral $B Z$-binding sites, after detergent removal, have already been demonstrated (Martini et al., 1983). The experiments undertaken here demonstrate detailed characterization of digitonin-solubilized periph eral BZ-binding sites from rat kidney without prior removal of the detergent.

\section{Materials and Methods}

Materials. [ $\left.{ }^{3} \mathrm{H}\right]$ Ro $5-4864$ was purchased from New England Nuclear (Boston, MA). Unlabeled BZs were kindly supplied by Drs. H. Gutmann and E. Kybur L, Holfrrlari-La Roche (Basel, Switzerland). Unlabeled PK 11195 was a generous gift from Dr. G. Le Fur (Pharmuka Laboratoires, Gennevilliers, France). 3-[(3-Chloramidopropyl)dimethylammonio]-1-propanesulfonate (CHAPS) was obtained from Calbiochem (La Jolla $\mathrm{CA}$ ). Digitonin, deoxycholate (DOC), and Triton X-100 were purchased from Sigma Chemical Co. (St. Louis, MO). All other compounds were purchased from commercial sources.

Membrane solubilization. Male Sprague-Dawley rats were decapitated and their kidneys were removed and frozen at $-20^{\circ} \mathrm{C}$. The kidney $(1 \mathrm{gm})$ was defrosted and homogenized in 50 vol of Tris- $\mathrm{HCl}$ buffer $(\mathrm{pH} \mathrm{7.4)}$ at $4^{\circ} \mathrm{C}$ with a Brinkman Polytron (setting 10 ) for $15 \mathrm{sec}$. The homogenate was centrifuged at $49,000 \times g$ for $15 \mathrm{~min}$, and the pellet was either homogenized in 60 vol of $50 \mathrm{~mm}$ Tris $\mathrm{HCl}$ buffer $(\mathrm{pH} \mathrm{7.4)}$ and used for binding studies or solubilized by detergents.

The pellet of washed membranes was homogenized in 60 vol of $50 \mathrm{~mm}$ Tris-HCl buffer $(\mathrm{pH} \mathrm{7.4)} \mathrm{containing} \mathrm{detergents} \mathrm{at} \mathrm{different} \mathrm{concentrations}$ and was stirred for $30 \mathrm{~min}$ at $4^{\circ} \mathrm{C}$. A portion of this material was assayed for binding activity, and the rest was centrifuged for 60 min at $100,000 \times$ $g$. I he resultant supernatant was diluted $1: 1$ and used as a soluble preparation, and the pellet was rehomogenized in the original volume of Tris- $\mathrm{HCl}$ buffer and tested for binding activity.

Binding assay. Binding activity of peripheral BZ-binding sites was assayed in $50 \mathrm{~mm}$ Tris- $\mathrm{HCl}$ buffer $(\mathrm{pH} \mathrm{7.4)} \mathrm{in} \mathrm{a} \mathrm{final} \mathrm{volume} \mathrm{of} 500 \mu \mathrm{l}$ containing 400 $\mu \mathrm{l}$ of soluble or membrane peripheral BZ-binding sites (80 to $160 \mu \mathrm{g}$ of protein) and $50 \mu \mathrm{l}$ of $\left[{ }^{3} \mathrm{H}\right] \mathrm{Ro}$ 5-4864 (0.5 to $40 \mathrm{nM}$ final concentration), in the absence (total binding) or presence (nonspecific binding) of $1 \mu \mathrm{M}$ unlabeled Ro $5-4864$ or $1 \mu \mathrm{M}$ unlabeled PK 11195 . After incubation for $60 \mathrm{~min}$ at $4^{\circ} \mathrm{C}$, 
samples were filtered under vacuum over Whatman GF/B filters, treated with polyethyleneimine (Bruns et al., 1983), and washed three times with $5 \mathrm{ml}$ of $50 \mathrm{~mm}$ Tris- $\mathrm{HCl}$ buffer $(\mathrm{pH} 7.4)$. Filters were placed in vials and counted for radioactivity.

\section{Results}

Effect of detergents on peripheral BZ-binding activity. The effect of a variety of detergents on the binding activity of peripheral BZ-binding sites was tested (Table I). Membranes were treated with detergents, and the binding activity tor $\left[{ }^{3} \mathrm{H}\right] \mathrm{Ro} \quad \mathrm{b}-4864$ was determined prior to ultracentrifugation. After the homogenate was spun for $60 \mathrm{~min}$ at $100,000 \times \mathrm{g}$, the binding activity was measured in the pellet and in the supernatant. More than $90 \%$ of the membrane-binding activity was lost by treatment with DOC $(0.5 \%)$, I riton X-100 (0.05\%), digitonin $(0.9 \%)$, or CHAPS $(0.9 \%)$. Peripheral BZ-binding sites exhibited particular sensitivity upon treatment with Triton $X-100$ but appeared to be less sensitive to Tween 20 . Approximately $70 \%$ of binding activity in the pellet was retained in the presence of as much as $0.9 \%$ Tween 20 , whereas only $15 \%$ or less of the binding activity in the pellet was obtained in the presence of other detergents such as CHAPS, DOC, digitonin, and Triton $X-100$. The binding activity in the supernatant under those conditions was very low or negligible. Among the detergents tested, only digitonin was found suitable for solubilization; approximately $21 \%$ of the binding activity present in the membranes was

TABLE I

Effect of detergents on the subcellular distribution of peripheral BZbinding sites in the rat kidney

Membranes were treated with detergents; then, specific binding of $\left[{ }^{3} \mathrm{H}\right]$ Ro 5.4864 (final concentration, $2.5 \mathrm{~nm}$ ) was determined on the membranes and, after ultracentrifugation, on the pellet and the supernatant, as described under "Materials and Methods." Values shown are means of three separate experiments which varied less than $10 \%$

\begin{tabular}{|c|c|c|c|}
\hline \multirow{2}{*}{ Detergent $(\%)$} & \multicolumn{3}{|c|}{ Specific Binding (\% Control) } \\
\hline & Membranes & Pellet & Supernatant ${ }^{a}$ \\
\hline & 101 & 103 & 1 \\
\hline \multicolumn{4}{|l|}{ Digitonin } \\
\hline 0.125 & 31 & 84 & 3 \\
\hline 0.25 & 19 & 32 & 21 \\
\hline 0.5 & 13 & 17 & 14 \\
\hline 0.9 & 4 & 16 & 6 \\
\hline \multicolumn{4}{|l|}{ CHAPS } \\
\hline 0.125 & 66 & 92 & 1 \\
\hline 0.25 & 47 & 72 & 3 \\
\hline 0.5 & 20 & 36 & 2 \\
\hline 0.9 & 6 & 13 & 1 \\
\hline \multicolumn{4}{|l|}{ DOC } \\
\hline 0.125 & 62 & 95 & 1 \\
\hline 0.25 & 28 & 59 & 2 \\
\hline 0.5 & 3 & 35 & 2 \\
\hline 0.9 & 1 & 15 & 1 \\
\hline \multicolumn{4}{|l|}{ Triton X-100 } \\
\hline 0.05 & 7 & $N D^{b}$ & 1 \\
\hline 0.125 & 2 & $\mathrm{ND}$ & 1 \\
\hline 0.25 & 1 & ND & 2 \\
\hline 0.5 & 1 & ND & 2 \\
\hline 0.9 & 1 & ND & 0 \\
\hline \multicolumn{4}{|l|}{ Tween 20} \\
\hline 0.125 & ND & 99 & 0 \\
\hline 0.25 & ND & 100 & 1 \\
\hline 0.5 & ND & 93 & 2 \\
\hline 0.9 & ND & 68 & 2 \\
\hline
\end{tabular}

${ }^{2}$ Diluted twice with buffer.

${ }^{\circ} \mathrm{ND}$, not determined. solubilized by $0.25 \%$ digitonin. Higher concentrations of detergent were found to be destructive and lower concentrations were less effective for solubilization. The yield obtained using DOC, Triton $X$ 100 , Tween 20 , or CHAPS was less than $20 \%$ of that obtained with digitonin solubilization.

In order to ascertain that digitonin-solubilized material did not contain membrane fragments, binding was conducted after additional ultracentrifugation at $100,000 \times g$ for $1 \mathrm{hr}$. More than $95 \%$ of the binding activity was retained in the supernatant. We were also unable to detect any binding activity in the solubilized material unless GF/B filters were treated with polyethyleneimine prior to filtration. Finally, the solubilized material stuck to DEAE cellulose, and more than $60 \%$ of the binding activity was eluted by $0.15 \mathrm{M}$ $\mathrm{NaCl}$ (data not shown). Solubilization experiments were performed using varying protein/detergent ratios of $0.5,1$, and $2 \mathrm{gm}$ of tissue/ $60 \mathrm{ml}$ of $0.25 \%$ digitonin. Since the highest solubilization was obtained using the ratio of $1 \mathrm{gm}$ of tissue $/ 60 \mathrm{ml}$ of $0.25 \%$ digitonin $(0.5,1$, and $2 \mathrm{gm}$ of tissue yielded $6 \%, 21 \%$, and $15 \%$ solubilization, respectively), this ratio was used routinely for solubilization.

Equilibrium binding. The binding of $\left[{ }^{3} \mathrm{H}\right] \mathrm{Ro} 5-4864$ at $4^{\circ} \mathrm{C}$ to membrane-bound and digitonin-solubilized binding sites was studicd. The concentration dependence of specific binding of $\left[{ }^{3} \mathrm{H}\right] \mathrm{Ro}$ $5-4864$ at equilibrium is shown in Figure 1. Specific binding of $\left[{ }^{3} \mathrm{H}\right]$ Ro 5-4864 to membrane-bound and solubilized peripheral BZbinding sites reached a plateau at $10 \mathrm{~nm}$, and this plateau was preserved up to $40 \mathrm{nM}$, which was the highest concentration tested.

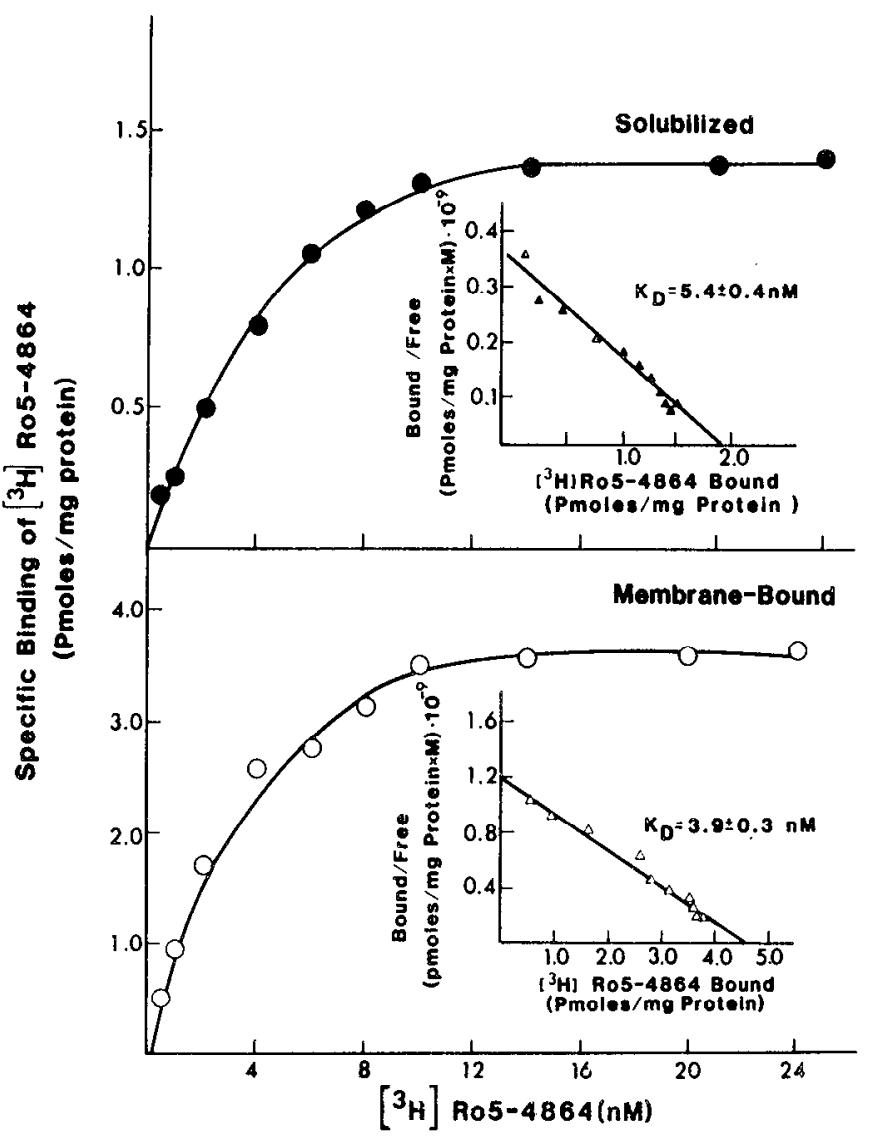

Figure 1. Saturation curve of specific $\left[{ }^{3} \mathrm{H}\right] \mathrm{Ro}$ 5-4864 binding to membrane-bound and digitonin-solubilized peripheral BZ-binding sites. Specific $\left[{ }^{3} \mathrm{H}\right]$ Ro 5.4864 binding (at $4^{\circ} \mathrm{C}$ for $60 \mathrm{~min}$ ) was determined as a function of its concentration (0.25 to $40 \mathrm{~nm}$ ), as described under "Materials and Methods"; only up to $24 \mathrm{~nm}$ is shown, although experiments were conducted up to $40 \mathrm{~nm}$. Insets show Scatchard plots of $\left[{ }^{3} \mathrm{H}\right] \mathrm{R}$ o 5-4864 binding to membrane-bound and solubilized preparations. The line is a regression line $(r=0.96)$ 
Nonspecific binding measured in the presence of $1 \mu \mathrm{M}$ unlabeled Ro 5-4864 was similar to the nonspecific binding measured in the presence of $1 \mu \mathrm{M}$ unlabeled PK 11195. The nonspecific binding at $2.5 \mathrm{nM}$ of $\left[{ }^{3} \mathrm{H}\right] \mathrm{Ro} 5-4864$ in the membrane-bound and the solubilized peripheral BZ-binding sites was $10 \%$ to $15 \%$ of total binding. Scatchard analysis of saturation curves of $\left[{ }^{3} \mathrm{H}\right] \mathrm{Ro}$ 5-4864 to peripheral BZ-binding sites yielded a linear Scatchard plot $(r=0.96)$, both in the membrane-bound and in the solubilized states. This indicates a single population of binding sites. The affinity of $\left[{ }^{3} \mathrm{H}\right]$ Ro 5-4864 to both membrane-bound and solubilized peripheral BZbinding sites was high, although the affinity to the solubilized sites was slightly lower than to the membrane-bound sites. The maximal binding capacity $\left(B_{\text {max }}\right)$ of the solubilized sites was only $42 \%$ of that of the membrane bound. Dilution of the solubilized material with buffer did not increase the $B_{\max }$ (data not shown). A $69 \%$ loss of activity was found when membranes were treated with $0.125 \%$ digitonin (Table I). Hence, the decrease in $B_{\max }$ in the solubilized sites was due to irreversible inactivation of these binding sites.

Kinetic experiments. The time course of $\left[{ }^{3} \mathrm{H}\right] \mathrm{Ro} 5-4864$ binding to solubilized peripheral BZ-binding sites is presented in Figure 2 (left). Binding appeared to reach equilibrium within about $60 \mathrm{~min}$ of incubation with $5 \mathrm{nM}\left[{ }^{3} \mathrm{H}\right] \mathrm{Ro} 5-4864$ at $4^{\circ} \mathrm{C}$. The half-maximal binding occurred at $10 \mathrm{~min}$. The association constant $\left(K_{+1}\right)$ calculated from these experimenls was $0.006 \mathrm{~min}^{-1} \mathrm{~nm}^{-1}$. The time course of dissociation of [ $\left.{ }^{3} \mathrm{H}\right] \mathrm{Ro}$ 5-4864 from solubilized BZ-binding sites is presented in Figure 2 (right). Half the amount of specific $\left[{ }^{3} \mathrm{H}\right] \mathrm{Ro}$ 5-4864/receptor complexes were dissociated after $22 \mathrm{~min}$. The dissociation constant rate $\left(K_{-1}\right)$ calculated from these studies was $0.032 \mathrm{~min}^{-1}$. The dissociation constant $\left(K_{\mathrm{D}}\right)$ obtained from these kinetic experiments was $5.3 \pm 0.6 \mathrm{~nm}$.

Drug specificity. In order to examine the similarity between solubilized and membrane-bound peripheral BZ-binding sites, the ability of unlabeled drugs to displace bound $\left[{ }^{3} \mathrm{H}\right] \mathrm{Ro}$ 5-4864 from the two preparations was tested (Table II). Clonazepam, Ro 151788, chlordiazepoxide, and methyl- $\beta$-carboline-3-carboxylate were inefficient $\left(\mathrm{IC}_{50}>10,000 \mathrm{nM}\right)$ in displacing $\left[{ }^{3} \mathrm{H}\right] \mathrm{Ro} 5-4864$ from either preparation. The affinity of flurazepam was slightly higher in both the membrane-bound and the solubilized prepara- tions. Ro 5-4864 was an order of magnitude morc potent than diazepam, and PK 11195 was the most potent in displacing bound $\left[{ }^{3} \mathrm{H}\right] \mathrm{Ro} 5-4864$ in both solubilized and membrane-bound peripheral BZ-binding sites. The correlation of rank order of potencies between membrane-bound and solubilized preparations was high ( $r$ $=0.99$ ).

Stability. The effect of heat $\left(60^{\circ} \mathrm{C}\right)$ on the binding activity of membrane-bound and solubilized peripheral BZ-binding sites is presented in Figure 3. More than $80 \%$ of the binding activity of the solubilized binding sites was destroyed after $10 \mathrm{~min}$ at $60^{\circ} \mathrm{C}$, whereas only $25 \%$ of the activity was lost when the binding sites were in the membrane state. After $60 \mathrm{~min}$ at $60^{\circ} \mathrm{C}$, the activity loss was $75 \%$ and $97 \%$ for the membrane-bound and the solubilized binding sites, respectively.

We also tested the stability of the solubilized binding sites at

TABLE ॥

Inhibition of [ $\left.{ }^{3} \mathrm{H}\right] \mathrm{Ro}$ 5-4864 binding in membrane bound and digitoninsolubilized peripheral BZ-binding sites from rat kidney

Incubation was performed for $60 \mathrm{~min}$ at $4^{\circ} \mathrm{C}$ with $2.5 \mathrm{nM}\left[{ }^{3} \mathrm{H}\right] \mathrm{Ro} 5-4864$ and in the presence of various concentrations of several drugs, as described under "Materials and Methods." Values shown are means of three separate experiments which varied less than $10 \%$.

\begin{tabular}{lcc}
\hline \multirow{2}{*}{ Inhibitor } & \multicolumn{2}{c}{$\mathrm{C}_{50}(\mathrm{M})^{2}$} \\
\cline { 2 - 3 } & Membrane-bound & Solubilized \\
\hline PK 11195 & $0.9 \times 10^{-9}$ & $1.0 \times 10^{-9}$ \\
Ro 5-4864 & $4.2 \times 10^{-9}$ & $3.9 \times 10^{-9}$ \\
Diazepam & $1.7 \times 10^{-7}$ & $1.2 \times 10^{-7}$ \\
Flurazepam & $6.1 \times 10^{-6}$ & $5.2 \times 10^{-6}$ \\
Clonazepam & $>10^{-5}$ & $>10^{-5}$ \\
Ro 15-1788 & $>10^{-5}$ & $>10^{-5}$ \\
Chlordiazepoxide & $>10^{-5}$ & $>10^{-5}$ \\
$\beta$-CCM & $>10^{-5}$ & $>10^{-5}$
\end{tabular}

${ }^{a} \mathrm{C}_{50}$, concentration of drug required to inhibit $50 \%$ of specific $\left[{ }^{3} \mathrm{H}\right] \mathrm{Ro} 5$ 4864 binding.

${ }^{b} \beta$-CCM, methyl- $\beta$-carboline-3-carboxylate.
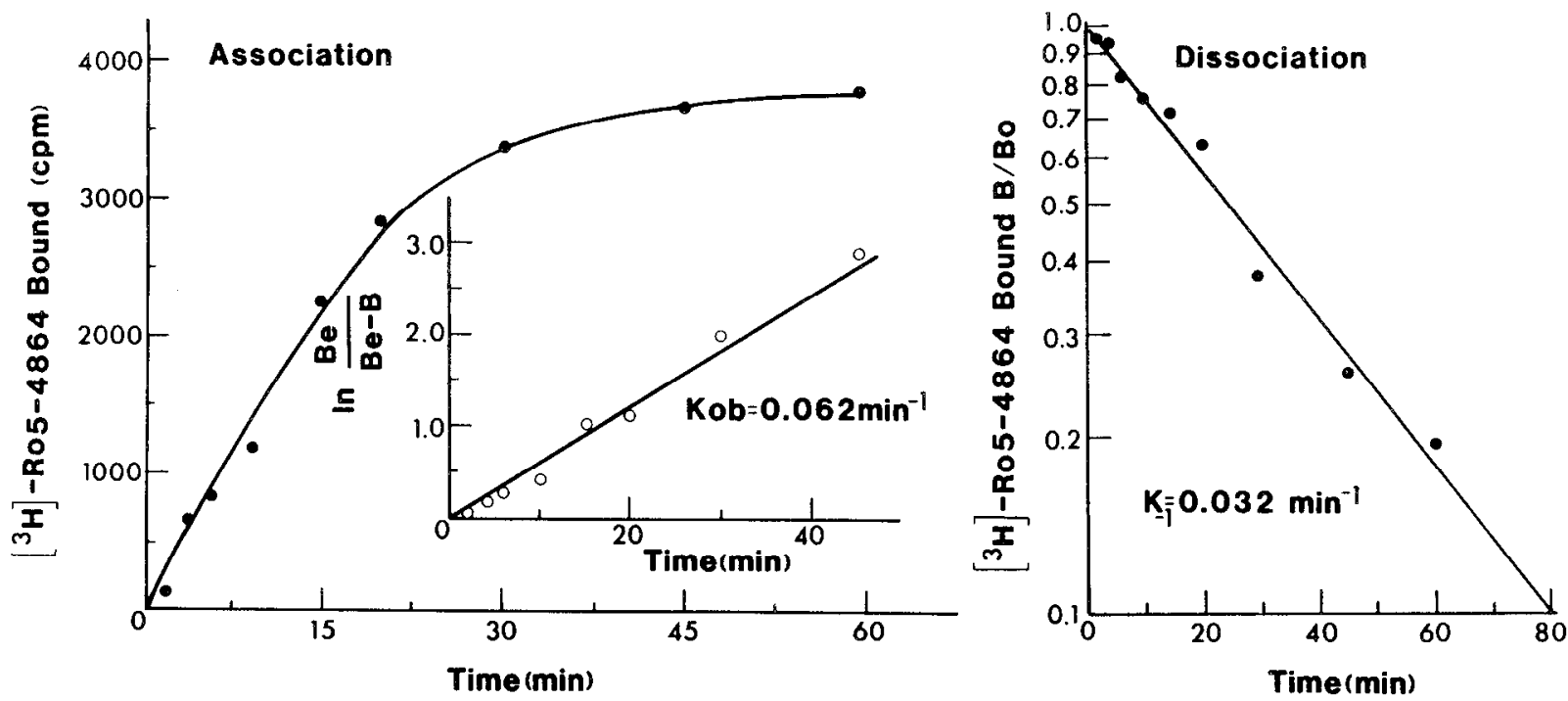

Figure 2. $\left[{ }^{3} \mathrm{H}\right] \mathrm{Ro}$ 5-4864 association to and dissociation from solubilized peripheral BZ-binding sites. Left, Association of $\left[{ }^{3} \mathrm{H}\right] \mathrm{Ro}$ 5-4864 to solubilized material incubated for various periods of time. Specific binding was determined as described under "Materials and Methods." Inset, Calculation of $K_{\mathrm{ob}}$ from the equation: $\ln \left[B_{e} /\left(B_{e}-B\right)\right]=K_{\mathrm{ob}} \times t$, where $B_{e}$ and $B$ are the concentrations of bound receptor at equilibrium and at time $t_{1}$ respectively, and $K_{\mathrm{ob}}$ is the observed constant. The association constant rale is $K_{+1}=K_{\mathrm{ob}} / L_{T}$, where $L_{T}$ is the free ligand concentration. Right, Dissociation of $\left[{ }^{3} \mathrm{H}\right] \mathrm{Ro} 5-4864$ from solubilized peripheral BZ-binding sites. Samples were incubated to equilibrium at $4^{\circ} \mathrm{C}$ in the presence of $5 \mathrm{nM}\left[{ }^{3} \mathrm{H}\right] \mathrm{Ro} 5-4864$. Dissociation was begun by addition of $10 \mu \mathrm{M}$ unlabeled $\left[{ }^{3} \mathrm{H}\right] \mathrm{Ro}$ 5-4864, and the samples were filtered immediately (zero time) and at the times indicated. Specific binding was determined as described under "Materials and Methods." Each point is the mean of three separate experiments with less than $10 \%$ variability. $\left.{ }^{3} \mathrm{H}\right] \mathrm{Ro}$ 5-4864 bound at $t_{0}$ was $0.6 \mathrm{pmol} / \mathrm{mg}$ of protein. 


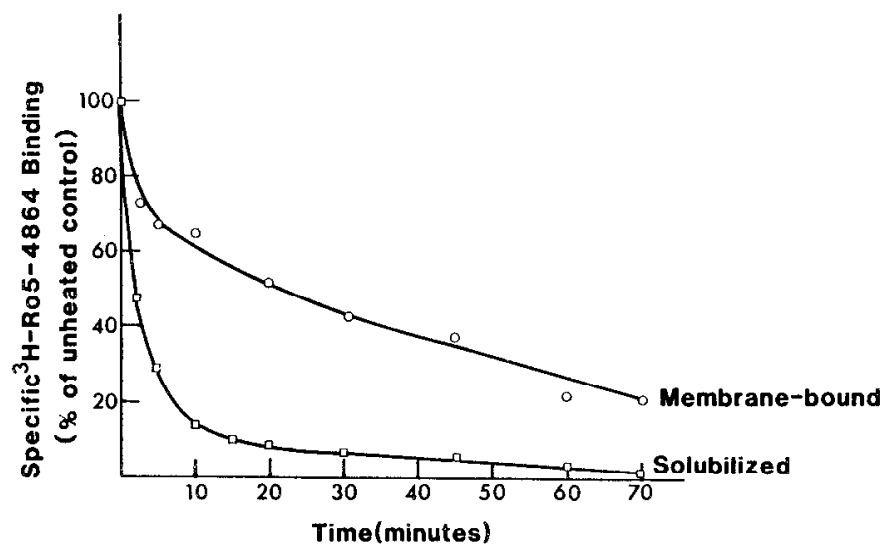

Figure 3. Time course of heat inactivation of membrane-bound and solubilized peripheral BZ-binding sites. Samples were heated at $60^{\circ} \mathrm{C}$ for various periods of time and then cooled, and the binding activity was determined as described under "Materials and Methods."

different conditions (Table III). More than 95\% of the activity was retained after $18 \mathrm{hr}$ at $4^{\circ} \mathrm{C}$ and more than $60 \%$ was retained after 4 days, which is of practical importance for purification studies which are time-consuming. Binding activity was also tested on solubilized material after overnight freezing at $-20^{\circ} \mathrm{C}$. Under these conditions, only $57 \%$ of the activity was retained. The solubilized binding sites were found to be stable when kept for $2 \mathrm{hr}$ at $25^{\circ} \mathrm{C}$, but at $37^{\circ} \mathrm{C}$ more than $30 \%$ of the activity was lost. These binding sites were also sensitive to urea and to guanidinium chloride. Seventy percent of the activity was lost at $2 \mathrm{M}$ urea, and all of the activity was destroyed at $4 \mathrm{M}$. More than $80 \%$ of the activity was lost at $1 \mathrm{~m}$ guanidinium chloride, and all of the activity was lost at $2 \mathrm{M}$.

\section{Discussion}

Whereas central BZ receptors have been solubilized by a variety of detergents, including Lubrol-PX (Yousufi et al., 1979), digitonin (Gavish et al., 1979), Triton X-100 (Lang et al., 19/9; Gavish and Snyder, 1980), DOC (Sherman-Gold and Dudai, 1980), and CHAPS (Stephenson and Olsen, 1982), studies on peripheral BZ-binding sites have thus far been conducted mainly on membrane-bound preparations. However, understanding the nature of these at the molecular level requires their solubilization. We chose kidney for solubilization experiments because it has rich concentrations of peripheral BZ-binding sites similar in drug specificity to those located in the brain. We found that, in contrast to central BZ receptors, which can be solubilized by a variety of detergents with no injurious effects on binding activity, the peripheral type is highly sensitive to detergent treatment. Most detergent concentrations commonly used for solubilization $(0.5$ to $1 \%)$ destroyed most of the membrane-binding activity (Table I). Tween $20(0.5 \%)$ was less destructive but was inefficient in solubilizing peripheral $\mathrm{BZ}$ binding; at higher concentrations, some siles were solubilized but were inactivated upon solubilization or inhibited by the presence of the detergent.

Even digitonin was destructive at routinely used concentrations, and the best results were obtained when relatively low digitonin concentrations $(0.25 \%)$ were used after being diluted twice prior to binding experiments. In order to ascertain that the peripheral BZ-binding sites were indeed solubilized, further ultracentrifugation was conducted, and more than $95 \%$ of the peripheral BZ-binding activity was found in the supernatant. In addition, the binding activity of the solubilized peripheral BZ-binding sites was undetectable unless GF/B filters were treated with polyethyleneimine, which also indicates that the material was in the soluble state. Further support is found in the fact that the peripheral BZ-binding sites were adsorbed on an ion-exchange column, after which $60 \%$ were eluted by salt.

A previous study has been made on the solubilization of peripheral BZ-binding sites (Martini et al., 1983) using 1\% Triton X-100. The detergent was removed subsequent to solubilization because it inhibits binding activity. Also according to our results, Triton $X$ 100 has an inhibitory effect on binding, and we found that as low a concentration as $0.05 \%$ inhibited most of the binding activity (Table I). It is unclear at exactly what stage the detergent must be removed: whether it must be removed immediately following solubilization or whether the solubilized material can be stored with the detergent until just prior to binding studies. If the binding sites are inactivated in the presence of Triton $X-100$, then the detergent must be removed immediately after solubilization. In such a case, purification procedures can be conducted only in very low concentrations of Triton $X-100$, in which state, however, precipitation of proteins may occur. In contrast, if the detergent can be left in the solubilized preparation without damaging the binding sites, then columns can be run at high Triton $X-100$ concentrations, and the detergent can be removed after chromatographic procedures. But even in such a case, the detergent must be removed, and from each fraction separately, prior to binding studies, which is a laborious and time-consuming procedure.

Digitonin, by contrast, which has recently been found to increase the affinity of peripheral BZ-binding sites at low concentrations (Gavish and Fares, 1985), is a more suitable detergent for solubilization and purification of these binding sites, since they are less sensitive to digitonin than to Triton $X-100$. Binding activity takes place at $0.125 \%$ digitonin. At such a concentration chromatographic procedures can be undertaken, since there is no danger of precipitation as long as the detergent is present.

Binding characteristics of membrane-bound and digitonin-solubilized peripheral BZ-binding sites were compared. On the one hand, $K_{D}$ values obtained al equilibrium for $\left[{ }^{3} \mathrm{H}\right] \mathrm{Ro}$ 5-4864 were similar in both preparations, although slightly lower for the membrane-bound preparation. On the other hand, the $B_{\max }$ for the solubilized preparations was less than $50 \%$ of that of the membrane-bound BZ-binding sites. The $K_{D}$ value for the solubilized material was also calculated from kinetic experiments. The value obtained from these studies was found to be similar to the value obtained from equilibrium experiments. The potency of different BZs was also tested in both preparations. We have shown that

\section{TABLE III}

Effect of various conditions on $\left[{ }^{3} H\right] R$ R 5-4864 binding to solubilized peripheral BZ-binding sites

Binding of $\left[{ }^{3} \mathrm{H}\right] \mathrm{Ro}$ 5-4864 (final concentration, $2.5 \mathrm{~nm}$ ) to solubilized peripheral BZ-binding sites at $4^{\circ} \mathrm{C}$ is as described under "Materials and Methods." Values shown are means of three separate experiments which varied less than $10 \%$.

\begin{tabular}{lc}
\hline \multicolumn{1}{c}{ Conditions } & $\begin{array}{c}\text { Specific Binding } \\
\text { (\% Control) }\end{array}$ \\
\hline Control (upon solubilization) & 100 \\
$18 \mathrm{hr}$ at $4^{\circ} \mathrm{C}$ & 98 \\
4 days at $4^{\circ} \mathrm{C}$ & 63 \\
$18 \mathrm{hr}$ at $-20^{\circ} \mathrm{C}$ & 57 \\
$2 \mathrm{hr}$ at $25^{\circ} \mathrm{C}$ & 97 \\
$2 \mathrm{hr}$ at $3 /^{\circ} \mathrm{C}$ & 68 \\
$30 \mathrm{~min}$ at $60^{\circ} \mathrm{C}$ & 3 \\
Urca & \\
$2 \mathrm{M}$ & 30 \\
$4 \mathrm{M}$ & 0 \\
Guanidinium chloride & \\
$1 \mathrm{M}$ & 18 \\
$2 \mathrm{M}$ & 0 \\
\hline
\end{tabular}


clonazepam, which binds tightly to the central $B Z$ receptor but not to the membrane-bound peripheral BZ-binding sites, also has weak affinity for the solubilized peripheral BZ-binding sites. We found that the BZ Ro 5-4864, which does not bind to the central BZ receptors, does bind tightly to both membrane-bound and solubilized peripheral BZ-binding sites. Of all the ligands tested, PK 11195 was the most potent ligand for peripheral BZ-binding sites in both preparations. We also found that diazepam binds to both prcparations with similar affinity, but with an order of magnitude lower than that of Ro 5-4684.

Since purification procedures are time-consuming, we examined the stability of the solubilized peripheral BZ-binding sites. No significant loss of binding activity was detected after $18 \mathrm{hr}$ at $4^{\circ} \mathrm{C}$, and more than $60 \%$ of the binding activity was retained after 4 days at $4^{\circ} \mathrm{C}$. This should enable application of purification procedures without major concern for the stability of the material. However, one should note that approximately $40 \%$ of the activity is lost by freezing, although this may be prevented by decreasing the detergent concentration by column chromatography followed by dialysis and lyophiiization. The fact that heating or treatment with urea or guanidinium chloride inactivated most of the binding activity indicates the presence of a protein-binding site in the solubilized preparation. Further studies are in progress to explore the molecular properties of the solubilized peripheral BZ-binding sites in the kidney and in the brain.

\section{References}

Bruns, R. F., K. Lawson-Wendling, and T. A. Pugsley (1983) A rapid filtration assay for soluble receptors using polyethyleneimine-treated filters. Anal. Biochem. 132: 74-81.

Chang, L. R., and E. A. Barnard (1982) The benzodiazepine/GABA receptor complex: Molecular size in brain synaptic membranes and in solution. J. Neurochem. 39: 1507-1518.

Davies, L. P., and V. Huston (1981) Peripheral benzodiazepine-binding sites in heart and their interaction with dipyridamole. Eur. J. Pharmacol. 73: 209-211.

Gavish, M. (1983) Protection of soluble benzodiazepine receptors from heat inactivation by GABAergic ligands. Life ScI. 33: 14/9-1483.

Gavish, M., and F. Fares (1985) The effect of freezing and thawing or of detergent treatment on peripheral benzodiazepine binding: The possible existence of an endogenous ligand. Eur. J. Pharmacol. 107: 283-284.

Gavish, M., and S. H. Snyder (1980) Soluble benzodiazepine receptors: GABAergic regulation. Life Sci. 26: 579-582.

Gavish, M., and S. H. Snyder (1981) $\gamma$-Aminobutyric acid and benzodiazepine receptors: Copurification and characterization. Proc. Natl. Acad. Sci. U. S. A. 78: 1939-1942.

Gavish, M., R. S. L. Chang, and S. H. Snyder (1979) Solubilization of histamine H-1, GABA, and benzodiazepine receptors. Life Sci. 25: 783790.

Lang, B., E. A. Barnard, L. R. Chang, and J. O. Dolly (1979) Putative benzodiazepine receptor: A protein solubilized from brain. FEBS Lett. 104: 149-153.

Marangos, J. P., J. Patel, J. P. Boulenger, and R. Clark-Rosenberg (1982) Characterization of peripheral-type benzodiazepine-binding sites in brain using $\left.{ }^{3} \mathrm{H}\right]$ Ro 5-4864. Mol. Pharmacol. 22: 26-32.

Martini, C., A. Lucacchini, G. Ronca, S. Hrelia, and C. A. Rossia (1982) Isolation of putative benzodiazepine receptors from rat brain membranes by affinity chromatography. J. Neurochem. 38: 15-19.

Martini, C., G. Giannaccini, and A. Lucacchini (1983) Solubilization of rat kidney benzodiazepine-binding sites. Biochem. Biophys. Acta 728: 289292.

Mohler, H., and T. Okada (1977) Benzodiazepine receptor: Demonstration in the central nervous system. Science 198: 849-851.

Mohler, H., T. Okada, P. H. Heitz, and J. Ulrich (1978) Biochemical identification of the site of action of benzodiazepines in human brain. Life Sci. 22: 985-996

Schoch, P., and H. Mohler (1983) Purified benzodiazepine receptor retains modulation by GABA. Eur. J. Pharmacol. 95: 323-324.

Schoemaker, H., M. Bliss, and H. I. Yamamura (1981) Specific high-affinity saturable binding of $\left[{ }^{3} \mathrm{H}\right] \mathrm{Ro}$ 5-4864 to benzodiazepine-binding sites in the rat cerebral cortex. Eur. J. Pharmacol. 71: 173-175

Sherman-Gold, R., and Y. Dudai (1980) Solubilization and properties of a benzodiazepine receptor from calf cortex. Brain Res. 198: 485-490.

Sigel, E., and E. A. Barnard (1984) A $\gamma$-aminobutyric acid/benzodiazepine receptor complex from bovine cerebral cortex: Improved purification with preservation of regulatory sites and their interactions. J. Biol. Chem. 259: 7219-7223.

Squires, R. F., and C. Braestrup (1977) Benzodiazepine receptors in rat brain. Nature 266: 732-734.

Stephenson, F. A., and R. W. Olsen (1982) Solubilization by CHAPS detergent of barbiturate-enhanced benzodiazepine/GABA receptor complex. J. Neurochem. 39: 15791586.

Taniguchi, T., J. K. T. Wang, and S. Spector (1980) Properties of $\left[{ }^{3} \mathrm{H}\right]$ diazepam binding to rat peritoneal mast cells. Life Sci. 27: 171-178.

Taniguchi, T., J. K. T. Wang, and S. Spector (1982) [ $\left.{ }^{3} \mathrm{H}\right]$ Diazepam-binding sites on rat heart and kidney. Biochem. Pharmacol. 31: 589-590.

Wang, J. K. T., T. Taniguchi, and S. Spector (1980) Properties of $\left[{ }^{3} \mathrm{H}\right]$ diazepam bındıng on rat blood platelets. Life Sci. 27: 1881-1888.

Wang, J. K. T., T. Taniguchi, M. Sugiura, and S. Spector (1981) Presence of benzodiazepine-binding sites in mouse thymocytes. Pharmacologist 23: 160 .

Weissman, B. A., G. T. Bolger, L. Isaac, S. M. Paul, and P. Skolnick (1984) Characterization of the binding of $\left[{ }^{3} \mathrm{H}\right] \mathrm{Ro} 5.4864$, a convulsant benzodiazepine, to guinea pig brain. J. Neurochem. 42: 969-975.

Yousufi, M. A. K., J. W. Thomas, and J. F. Tallman (1979) Solubilization of benzodiazepine-binding site from rat cortex. Life Sci. 25: 463470 . 